Wijde Bay. The radiating-point lies somewhat north-west of the centres of each area, with supplementary radiating-points on the north and east. The group of peaks including the Three Crowns may be regarded as nunatakkr. The valley-bound ground-ice does not necessarily travel in the same direction as that of the surface. The effect of nunatakkr on the surface of the ice-sheet was studied, and from this it was often found possible to infer the existence and position of buried mountain-ridges. On the stoss-seite of a nunatak moraine-material is often discharged. The movement of the ice has frequently converted the ice-bridges across crevasses into arches and tunnels, some of which carry part of the drainage of the ice-sheet.

Portions of old stranded ground-moraines, formed when the ice was more extensive, were sometimes found to have fallen upon the lowered ice-sheet and to be mingled with modern moraine-material. Euglacial and superficial rivers are described, and one of the latter was found to be depositing gravelly material along a line at right angles to the valley down which the ice was flowing.

Certain observations on the rate of movement of the ice-sheet seem to indicate that this is not less than 15 to 20 feet in 24 hours; while the glaciers near the sea-margin appear to be travelling about 25 feet in the same time.

The action of sea-ice is described, and it is inferred that a certain amount of rounding and scratching of shore-rocks, and possibly part of the smoothing of boulders, may be due to this agent.

4. "Additional Notes on the Vertebrate Fauna of the Rock-Fissure at Ightham (Kent)." By E. T. Newton, Esq., F.R.S., F.G.S.

Since the previous paper on the Ightham-fissure fauna published by this Society about five years ago, numerous additional specimens have been obtained, not only by Mr. Lewis Abbott, but also by Mr. Frank Corner and Mr. Kennard.

The present paper gives a very brief account of the new forms which have been discovered and identified during the last five years, with remarks upon some important additional remains of Mustela robusta, and of the Spermophilus which is now referred to the species erythrogenoides of Falconer. This paper adds some 19 new forms to the fauna of the Ightham fissure.

* The next Meeting of the Society will be held on Wednesday, November 8th, 1899.

\title{
CORIESPOINDEINOE.
}

\section{ROCK-WEATHERING, SERPENTINIZATION, ETC.}

Srr,-Both Mr. Merrill and Mr. Holland deserve the thanks of geologists for their suggestive papers on certain forms of rock change, and the distinction drawn by the former (p. 354, GroL. MAG., August, 1899) between ordinary 'weathering' and more deep-seated changes in rocks is of great importance. The subject is one which my own work has often brought before me, though, as other 
questions bad prior claims, I have never been able to investigate it: systematically. And it is one beset with difficulties, especially when we are dealing with rather old rocks, not the least being that of determining when the alteration for which we have to account, has taken place. But I have always tried, so far as was possible, to call attention to any mineral changes which seemed distinctive, and have sometimes ventured to suggest a cause for them. The subject would well repay any young geologist with sufficient leisure, and on this account, with the same motive as Mr. Merrill, I will venture to offer a few remarks suggested by his paper. As regards ' serpentinization' I have come to the same conclusion as himself, viz., that the change is deep-seated rather than superficial, and that. the same is true of certain other hydrons minerals, though it may not hold with some at least of the zeolites. But the anomalies which mineral change presents are apparently considerable. As an example we may select the conversion of augite into hornblende. Sometimes a crystalline grain of the former mineral may pass into one of the latter by a change seemingly no more than paramorphic; sometimes it may break up into a group of sinaller grains, not retaining exactly the original outline. Sometimes, carrying this further, it may form one or more elongated crystals (this, as I have pointed out, seems connected with pressure) ; and sometimes it may be converted into a more or less fibrous and matted mass, in which case not seldom some chemical alteration seems to haye taken place. Again, as another anomaly, some light-coloured augites seem very stable, as in certain picrites and granites; while others, as in some hemithrenes, change rather readily into serpentine. But in a micatrap the augite, probably also not rich in iron, seems to be very uustable, not, however, altering to hornblende. In one dolerite the augite seems to change more readily than the felspar, in another the reverse. Felspar sometimes changes into quartz and white mica, sometimes undergoes other alterations. Here, as in some other cases, much probably depends upon whether the water present is 'stagnant' or in motion. It would be easy to continue the list, but this may suffice to give some idea of the problems presented, and when they have been solved we may proceed to those presented by the devitrification of glassy igneous rocks. Suffice it to say that the changes in a mineral seem to be the outcome of two separate causes ; one, its chemical composition; the other, its environment, the principal factors in the latter being water, pressure, and heat. The best way of attacking the problems will be by first studying the simpler cases, viz., those in which we can be reasonably certain that one factor in the environuent has so far dominated over the others, that they may be neglected; and then proceeding to the more complicated cases. Of this I think we may be certain, that in nature, with the same materials, similar causes produce identical results, and dissimilar causes the contrary.

T. G. Bonney. 